\title{
Mechanical Properties and Conversion Relations of Strength Indexes for Stone/Sand-Lightweight Aggregate Concrete
}

\author{
Xianggang Zhang, ${ }^{1,2}$ Dapeng Deng, ${ }^{1}$ and Jianhui Yang $\mathbb{B D}^{1,2}$ \\ ${ }^{1}$ Henan Province Engineering Laboratory of Eco-architecture and the Built Environment, Henan Polytechnic University, \\ Jiaozuo 454000, China \\ ${ }^{2}$ School of Civil Engineering, Henan Polytechnic University, Jiaozuo 454000, China
}

Correspondence should be addressed to Jianhui Yang; yangjianhui@hpu.edu.cn

Received 18 May 2018; Revised 10 July 2018; Accepted 22 July 2018; Published 17 September 2018

Academic Editor: Barbara Liguori

Copyright (c) 2018 Xianggang Zhang et al. This is an open access article distributed under the Creative Commons Attribution License, which permits unrestricted use, distribution, and reproduction in any medium, provided the original work is properly cited.

\begin{abstract}
This is a study of the basic mechanical properties of specified density shale aggregate concrete, which is based on different replacement rates in stone-lightweight aggregate concrete (stone-LAC) and sand-lightweight aggregate concrete (sand-LAC). They were prepared by replacing the ceramsite and pottery sand with stone and river sand, respectively. Many tests were performed regarding the basic mechanical property indexes, including tests of cube compressive strength, axial compressive strength, splitting tensile strength, flexural strength, elastic modulus and Poisson's ratio. The failure modes of specified density shale aggregate concrete were obtained. The effects of replacement rates on the mechanical property indexes of specified density shale aggregate concrete were analyzed. Calculation models were implemented for elastic modulus, for the conversion relations between the axial compressive strength and the cube compressive strength, and for the relations between the tension-compression ratio and Poisson's ratio. It was shown that when the replacement rate of stone or river sand increased from $0 \%$ to $100 \%$, the cube compressive strength of stone-LAC and sand-LAC increased, respectively, by $55 \%$ and $25 \%$, the axial compressive strength increased, respectively, by $91 \%$ and $72 \%$, splitting tensile strength increased, respectively, by $99 \%$ and $44 \%$, and the flexural strength increased, respectively, by $46 \%$ and $26 \%$. Similarly, the elastic modulus of stone-LAC and sand-LAC increased, respectively, by $16 \%$ and $30 \%$. However, Poisson's ratio for stone-LAC decreased first and then increased, eventually increased by $11 \%$; Poisson's ratio for sand-LAC only reduced gradually, eventually reduced by $67 \%$. After introducing the influence parameter for the replacement rate, the established calculation models become simple and practical, and the calculation accuracies are favorable.
\end{abstract}

\section{Introduction}

The rapid development of the construction industry in recent years has been marked by intensifying research and development for full-lightweight aggregate concrete (FLAC), where the aggregate consists of ceramsite and shale pottery. Compared with ordinary concrete, FLAC can effectively alleviate the environmental destruction resulting from the exploitation of normal stone and sand. FLAC also has the advantage of low density, as well as favorable thermal insulation, and fine frost resistance [1-3]. However, there are some weaknesses for FLAC, for example, FLAC can't be widely used because of its high cost [4]. In addition, the tensile strength of FLAC was about 0.8 times that of normal concrete under same condition [5]. In particularly, compared to ordinary concrete, the brittleness of FLAC reflected as proportional strain ratio is about $20 \%$ higher than of ordinary concrete [6], it also indicates that the tensile strength or shearing strength of FLAC is lower than of ordinary concrete. In order to improve the physical and mechanical performance of FLAC, some normal aggregate instead of partial lightweight aggregate is employed in FLAC to create a new kind of specified density lightweight aggregate concrete. In general, the density of specified density lightweight aggregate concrete varies in the range of $1840-2240 \mathrm{~kg} / \mathrm{m}^{3}$ [7]. Thus, in this paper, two new specified 
density shale aggregate concretes are formulated. The concrete with ordinary stone instead of partial coarse lightweight aggregate is referred to as stone-LAC for simplicity; similarly, the concrete with some ordinary river sand instead of fine lightweight aggregate is referred to as sandLAC. Compared to FLAC, stone-LAC and sand-LAC have higher strength and elasticity modulus, lower shrinkage deformation, and less pumping and construction difficulty. Moreover, it is worth mentioning that under this methodology, construction costs are observably reduced $[8,9]$.

In this work, failure processes and failure mechanisms of stone-LAC and sand-LAC will be revealed based on comprehensive test data. Furthermore, conversion relations among strength indexes will be established by regression analysis. The material parameters underlying the structural design of stone-LAC and sand-LAC will be provided with a scientific foundation through the aforementioned methods.

Without a doubt, lightweight aggregate assumes a leading role in LAC properties, which include mechanics, durability, thermal conductivity, etc. In other words, different kinds of lightweight aggregate can produce LACs with distinguishable properties. In previous studies, quantities of lightweight materials were selected as aggregate in lightweight concrete. The lightweight aggregates could be classified into the following categories: natural (such as pumice, diatomite, volcanic ash, etc.) and artificial (such as perlite, expanded shale, clay, slate, sintered pulverized-fuel ash, etc.) [10]. Onoue et al. [11] presented the result that the shockabsorbing capability of lightweight concrete utilizing volcanic pumice aggregate was superior to the control concrete using crushed limestone as coarse aggregate. Topçu and Işıkdağ [12] and Sengul et al. [13] studied the effect of expanded perlite aggregate on the properties of lightweight concrete; they proved that increased use of expanded perlite aggregate resulted in less strength and less weight in the concrete, while at the same time, thermal conductivity was substantially improved.

In contrast to LAC with other lightweight aggregates, LAC with shale aggregate originating from natural shale has not been as well researched. Natural shale can be manufactured into shale ceramsite and shale pottery sand via high temperature and calcination, which has been generally adopted as lightweight aggregate $[14,15]$. Shale aggregate is suitable for wear resistance, corrosion resistance, and adsorption [16-18], it also has the advantages of weight, compressibility, heat retention, seismic resistance, and nonradioactivity. Thus, shale aggregate has been deemed as an appropriate material for reducing energy usage in buildings [19, 20]. These qualities, combined with its low price, have helped spur its growing application in agriculture and other industries [21-23]. However, the mechanical properties of shale LAC require more study for its continued development and application.

At present, many experimental and theoretical studies on the physical and mechanical properties of FLAC have been conducted. Tasdemire et al. [24] found that lightweight aggregates can reduce the thermal conductivity of FLAC and established a significant correlation between thermal conductivity and unit weight for the concrete. Zaetang et al. [25] showed that using diatomite pumice as coarse aggregates in full-lightweight pervious concrete can reduce its density and thermal conductivity by 3-4 times compared to previous concrete containing natural aggregate. Kaffetzakis and Papanicolaou [26] experimented with the bond behavior of reinforcement in full-lightweight aggregate selfcompacting concrete. They reported that the maximum bond stress under normalization increased when each of the following is increased: rebar diameter, bond length, and the oven-dry density of the mix. In short, these new FLACs possessed satisfactory physical properties, but their mechanical properties were still inferior to ordinary concrete.

Several groups have attempted to improve the poor mechanical properties of FLAC through modification. Miller and Tehrani [27] mixed rubber into FLAC to prepare 36 beam specimens. The results showed that the tire-derived aggregates had reduced the mechanical strength, but did induce a partial enhancement of the ductility and toughness. Aslam et al. [28] produced high-strength specified density lightweight aggregate concrete by using blended coarselightweight aggregates. Test results showed that oil palm shell in oil-palm-boiler clinker concrete contributed to reductions in density and in the mechanical property indexes. $\mathrm{Ma}$ et al. [29] manufactured modified expanded-clay ceramsite concrete with an inorganic polymer compound and conducted failure tests at room temperature before and after exposure to high temperatures. Results showed that the polymer selected for the modification material decomposed gradually to produce volatiles as the temperature increased, which are risks for concrete spalling. However, creating channels for vapor release may mitigate spalling. Chung et al. [30] evaluated the effects of crushed and expanded waste glass aggregates on the material properties of lightweight concrete, respectively. The derived results supported the feasibility of both glass aggregates being used as alternative lightweight aggregates.

The above studies focused either on lightweight aggregate or on FLAC, specifically modified FLAC. Although the attempted modifications produced satisfactory results, the modification mechanism and the relations among strength indexes were not understood, which constrained further study and reduced the number of potential engineering applications. More importantly, no report that describes the mechanical properties and conversion relations of strength indexes for specified density shale aggregate concrete with ordinary stone or ordinary river sand has been found up to now. The work described in this paper is an attempt at addressing these unknowns.

In this investigation, FLAC graded as LC35 was deemed as the control concrete. According to the exchange method of equal volume, the shale ceramsite and pottery sand in control concrete were replaced by stone and river sand to prepare stone-LAC and sand-LAC, respectively. The investigation focused on the failure mechanism and influence of the replacement rate of stone and river sand in order to establish conversion formulas for strengths, as well as deformation, and tension-compression ratio. The information gained from this research may help expand the number of 
engineering applications for concrete structures produced by specified density shale aggregate.

\section{Test Program}

2.1. Test Raw Materials. The cement was 42.5-grade ordinary portland cement produced by a company in Jiaozuo, China. The mix water was tap water; coarse aggregate was comprised of natural crushed stone and ceramsite; ceramsite is shown in Figure 1(a). Ceramsite is a ceramic material with different particle sizes and is made from natural shale after crushing, sieving, high-temperature calcination, and screening. The main properties of coarse aggregate are displayed in Table 1. Two kinds of fine aggregate are pottery sand and ordinary river sand, pottery sand is shown in Figure 1(b), the main properties of fine aggregate are shown in Table 2, It can be seen that the accumulation density of ceramsite and pottery is lower than that of stone and river sand. The higher porosity of ceramsite and pottery make them absorb water more easily. The ceramsite was submerged in water for 12 hours before it was used. Fly ash adopted third grade fly ash. The fly ash was $25 \%$ of the total amount of cementing material. The main ingredient of the water reducing agent was a $\beta$-high condensation compound of naphthalene sulfonic acid formaldehyde, and its mixing amount is $1 \%$ of the total cementing material.

2.2. Test Method. The replacement rate of coarse aggregate in stone-LAC is defined as the loose volume of stone within the aggregate. Five kinds of replacement rate of coarse aggregate in stone-LAC are expressed as $r(0 \%, 25 \%, 50 \%, 75 \%$, and $100 \%)$. When $r=0 \%$, the stone-LAC is an all-lightweight aggregate concrete. The fine aggregate replacement rate of sand-LAC is the loose volume of river sand, which accounts for the loose aggregate volume. Three aggregate replacement rates for the sand-LAC fine aggregate $(0 \%, 50 \%, 100 \%)$ have been selected. When $r=0 \%$, the sand-LAC is an alllightweight aggregate concrete. Each replacement rate contained six $150 \times 150 \times 150 \mathrm{~mm}$ cube specimens, which are divided into two groups based on the intended test: compressive strength and splitting tensile strength. Each replacement rate also contained three prism specimens of $150 \times 150 \times 300 \mathrm{~mm}$, which were used for the determination of axial compressive strength, elastic modulus, and Poisson's ratio. Lastly, each rate included another three prism specimens of $150 \times 150 \times 550 \mathrm{~mm}$, which were used for the determination of flexural strength. The test specimens were formed in standard sizes.

The design strength of all-lightweight aggregate concrete was LC35. According to the technical specification for lightweight aggregate concrete (JGJ51-2002), the loose volume method is used for the design and calculation of the mix ratio for all-lightweight aggregate concrete. According to previous research [31-33], the mix proportion of alllightweight aggregate concrete was based on the proportion of the loose volume of coarse or fine aggregate. The quality coordination of stone-LAC and sand-LAC under each replacement rate are shown in Table 3. Under different mix proportions in Table 3, the slump values of specified density shale aggregate concrete were measured. As shown in Figure 2, after the fresh concrete was prepared, the slump cylinder was rinsed and placed on an wetting plate, then the representative concrete was loaded into the cylinder fully. According to the Chinese code for test method of performance on ordinary fresh concrete (GB/T50080-2016), the slump cylinder was lifted and placed beside the cone concrete, and the vertical distance from the top of the cylinder to the center of the concrete top was the slump value. The result shows that the slump values of stone-LAC and sand-LAC are at the range of $150 \mathrm{~mm}$ to $180 \mathrm{~mm}$, it indicates that specified density shale aggregate concrete has good working performance.

The strength index of specified density shale aggregate concrete was determined according to the test method of mechanical properties of ordinary concrete (GB500812002), where a lateral and longitudinal strain patch was attached to the middle of a side prismatic specimen. The elastic modulus and Poisson's ratio were obtained by using the method of force controlled loading, and the strain values were collected.

\section{Results and Discussion}

3.1. Failure Process and Failure Mode. At the initial stage of loading, there was no obvious change in the surface of the cube. As loading increased, the specimen internal stress increased and produced a weak "crackling" sound. Continued loading led to the emergence of smaller cracks and microcracks on the surface of the test specimen. These cracks gradually expanded and passed through the specimen bulk until upon the limit load, the test specimen was ultimately destroyed. As shown in Figure 3, the failure surface of the cube test specimen was oriented about 60 degrees relative to the center of the test specimen, while the upper and lower specimen surfaces were essentially intact, and more and more defect appeared near the middle area, so the final failure mode was similar to the inverted pyramid. The damage to the specified density shale aggregate concrete was caused by the joint between the ceramsite itself and the cement mortar.

The prism began to fail when microcracks emerged on the surface, which then expanded through the specimen before it was finally destroyed by massive flaking. Destroyed prismatic Specimens are shown in Figure 4. The damage to the specified density shale aggregate concrete specimen was also caused by the joint between the ceramsite and the cement mortar. Figure 4(a) shows that the increase in the stone replacement rate is accompanied by more inclined cracks on the stoneLAC prism specimen; at $100 \%$ replacement, the inclined cracks of the stone-LAC appeared through the upper and lower specimen. On Figure 4(b), the increase of river sand replacement rate was accompanied by a reduced degree of destruction for the sand-LAC specimen, where the failure area was concentrated in the middle of the test specimen, while the upper and lower ends remained intact.

The splitting and flexural failure modes of specified density shale aggregate concrete specimens are shown in Figures 5 and 6 . Due to the low strength of shale ceramsite 


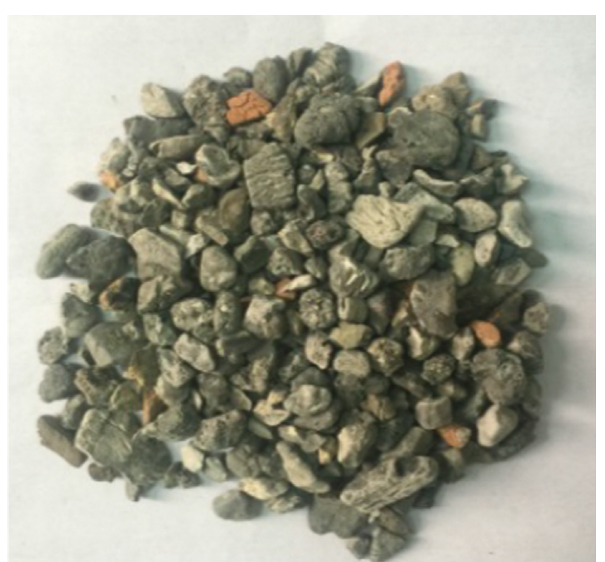

(a)

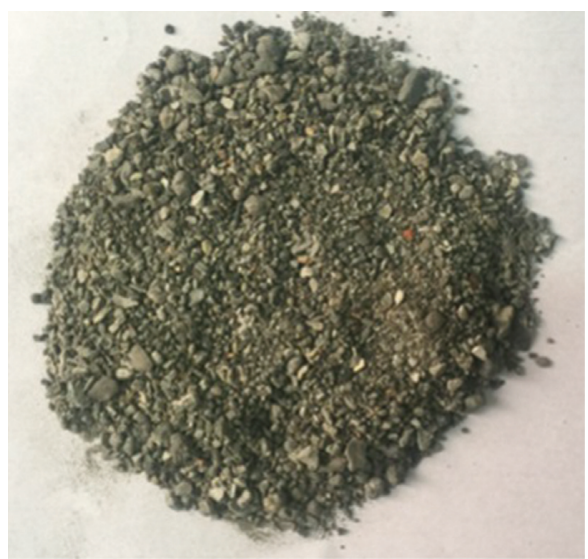

(b)

FIGURE 1: Shale aggregate: (a) ceramsite; (b) pottery sand.

TABLE 1: The basic property indexes of ceramsite and crushed stone.

\begin{tabular}{lccccc}
\hline Type & Particle size $(\mathrm{mm})$ & Bulk density $\left(\mathrm{kg} / \mathrm{m}^{3}\right)$ & Needle-like content $(\%)$ & Mud content (\%) & Cylinder pressure strength $(\mathrm{MPa})$ \\
\hline Ceramsite & $5-15$ & 660 & - & - & 4.5 \\
Crushed stone & $5-15$ & 1434 & $<10.0$ & $<1.0$ & 10.7 \\
\hline
\end{tabular}

TABLE 2: The basic property indexes of pottery sand and river sand.

\begin{tabular}{lcccc}
\hline Type & Particle size $(\mathrm{mm})$ & Bulk density $\left(\mathrm{kg} / \mathrm{m}^{3}\right)$ & Mud content $(\%)$ & Fineness modulus \\
\hline Pottery sand & $\leq 5$ & 880 & $<1.0$ & 3.15 \\
River sand & $\leq 5$ & 1472 & $<1.0$ & 2.85 \\
\hline
\end{tabular}

TABLE 3: Quality mix proportion of stone-lightweight and sand-lightweight aggregate concrete $\left(\mathrm{kg} / \mathrm{m}^{3}\right)$.

\begin{tabular}{|c|c|c|c|c|c|c|c|c|c|}
\hline Type & $r$ & Cement & Fly ash & Ceramsite & Crushed stone & Pottery sand & River sand & Water & Water reducer \\
\hline \multirow{5}{*}{ Stone-LAC } & $0 \%$ & 472 & 159 & 444 & 0 & 408 & 0 & 171 & 6.31 \\
\hline & $25 \%$ & 472 & 159 & 333 & 241 & 408 & 0 & 171 & 6.31 \\
\hline & $50 \%$ & 472 & 159 & 222 & 482 & 408 & 0 & 171 & 6.31 \\
\hline & $75 \%$ & 472 & 159 & 111 & 723 & 408 & 0 & 171 & 6.31 \\
\hline & $100 \%$ & 472 & 159 & 0 & 964 & 408 & 0 & 171 & 6.31 \\
\hline \multirow{3}{*}{ Sand-LAC } & $0 \%$ & 472 & 159 & 444 & 0 & 408 & 0 & 171 & 6.31 \\
\hline & $50 \%$ & 472 & 159 & 444 & 0 & 204 & 341 & 171 & 6.31 \\
\hline & $100 \%$ & 472 & 159 & 444 & 0 & 0 & 682 & 171 & 6.31 \\
\hline
\end{tabular}

and pottery sand, the fracture surfaces of stone-LAC and sand-LAC existed not only in cement paste but also in a large number of lightweight aggregate. The splitting tensile test specimen was destroyed along two directions: first in the vertical direction, and while the second direction was oriented at an angle of $70-90^{\circ}$ with respect to the horizontal plane of the fracture resistant specimen.

\subsection{Influence on Mechanical Strength}

3.2.1. Compressive Strength. The cube compressive strength $\left(f_{\mathrm{cu}}\right)$ and axial compressive strength $\left(f_{\mathrm{c}}\right)$ of specified density shale aggregate concrete were measured via a common concrete mechanics performance test method (GB500812002), $\quad 150 \times 150 \times 150 \mathrm{~mm}$ cube specimens were used to measured $f_{\mathrm{cu}}$ and $150 \times 150 \times 300 \mathrm{~mm}$ prism specimens were used to measured $f_{c}$, the results are shown in Table 4 . It can be seen that the cube compressive strength and the axial compressive strength of specified density shale aggregate concrete increased with the increase of the replacement rate of stone and river sand $(r)$. This is explained by the stone and the river sand possessing higher strength than the ceramsite and the pottery. The increase of the replacement rate is accompanied by a higher proportion of stone and river sand in the light and sand light concrete, which then increases the compressive strength of the specified density shale aggregate concrete.

The increase in compressive strength for the stone-LAC at each replacement rate (Table 4 ) is $10.3 \%, 5.1 \%, 12.8 \%$ and $18.8 \%$, respectively; the increase in compressive strength for the sand-LAC is $17.6 \%$ and $6.4 \%$, respectively. It can be seen that with the increase of replacement rate, the increase of 


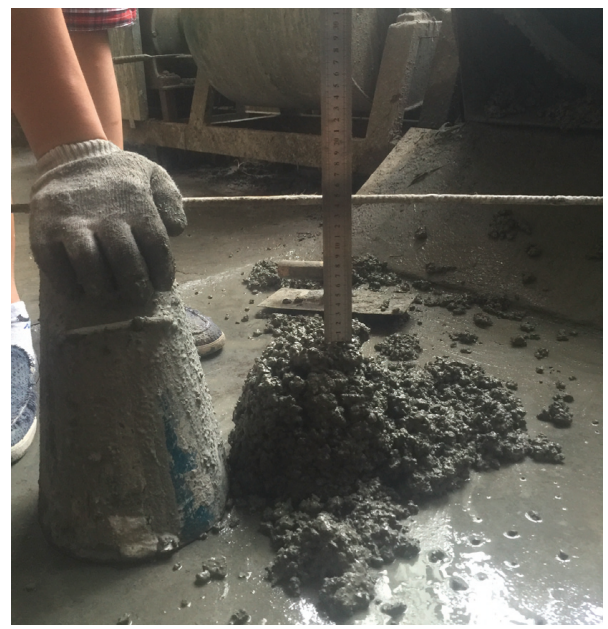

Figure 2: Measuring method of slump value.

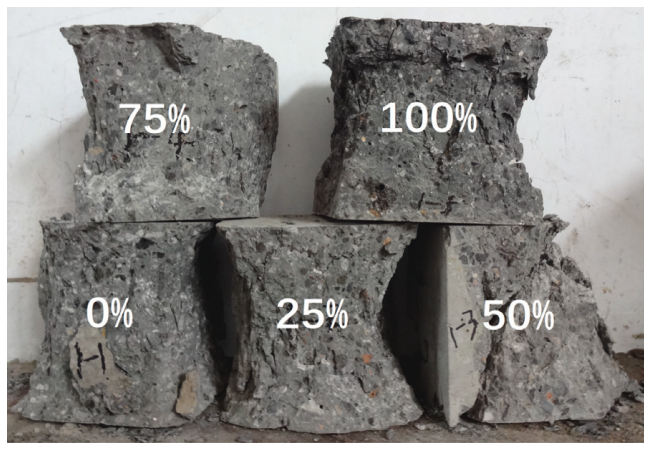

(a)

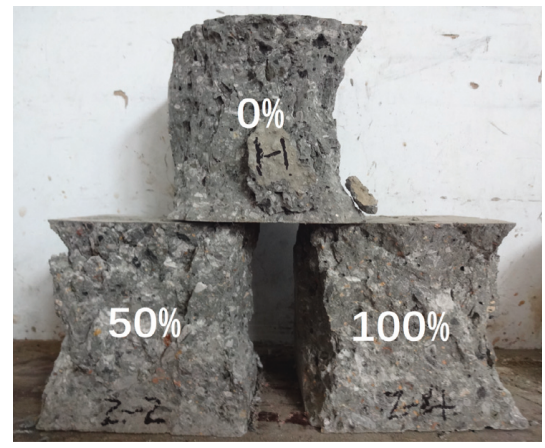

(b)

Figure 3: Cube compressive failure mode: (a) stone-LAC; (b) sand-LAC.

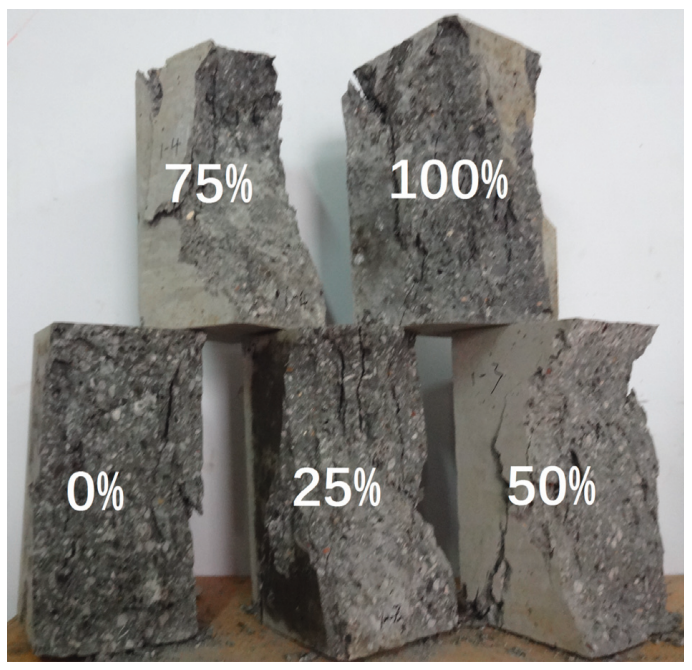

(a)

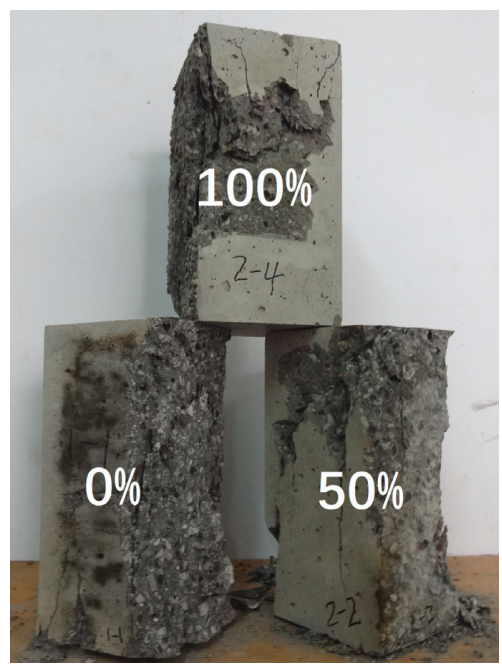

(b)

Figure 4: Axial compression failure mode: (a) stone-LAC; (b) sand-LAC.

cube compressive strength of stone-LAC decreased first and then increased, while the increment of sand-LAC compressive strength decreased. The cube compressive strength for the stone-LAC at each replacement rate increased by $10.3 \%, 15.9 \%, 30.7 \%$, and $55.3 \%$ compared with alllightweight aggregate concrete, respectively. The cube 


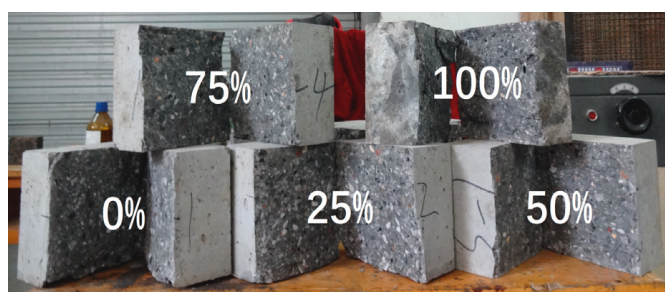

(a)

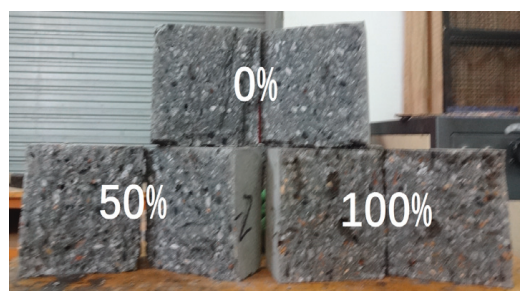

(b)

FIGURE 5: Splitting tensile failure mode: (a) stone-LAC; (b) sand-LAC.

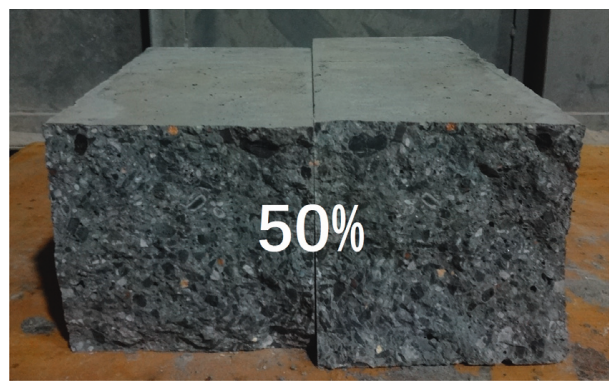

(a)

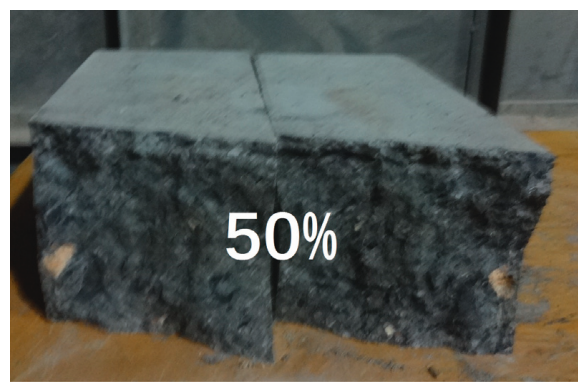

(b)

Figure 6: Flexural failure mode: (a) stone-LAC; (b) sand-LAC.

TABLE 4: Compressive strength of specified density shale aggregate concrete.

\begin{tabular}{|c|c|c|c|c|c|}
\hline Type & $r(\%)$ & Dry apparent density $\left(\mathrm{kg} / \mathrm{m}^{3}\right)$ & $f_{\mathrm{cu}}(\mathrm{MPa})$ & $f_{\mathrm{c}}(\mathrm{MPa})$ & $f_{\mathrm{c}} / f_{\mathrm{cu}}$ \\
\hline \multirow{5}{*}{ Stone-LAC } & 0 & 1330 & 35.8 & 24.7 & 0.69 \\
\hline & 25 & 1450 & 39.5 & 33.6 & 0.85 \\
\hline & 50 & 1550 & 41.5 & 35.4 & 0.85 \\
\hline & 75 & 1740 & 46.8 & 40.7 & 0.87 \\
\hline & 100 & 1940 & 55.6 & 47.3 & 0.85 \\
\hline \multirow{3}{*}{ Sand-LAC } & 0 & 1330 & 35.8 & 24.7 & 0.69 \\
\hline & 50 & 1510 & 42.1 & 35.9 & 0.85 \\
\hline & 100 & 1550 & 44.8 & 42.4 & 0.95 \\
\hline
\end{tabular}

compressive strength for the sand-LAC at each replacement rate increased by $17.6 \%$ and $25.1 \%$, respectively, compared with all-lightweight aggregate concrete. At $r=100 \%$, the stone-LAC experienced a much greater increase in cube compressive strength compared with all-lightweight aggregate concrete.

At each replacement rate, the stone-LAC axial compressive strength increased by $36 \%, 5.4 \%, 15 \%$ and $16.2 \%$, respectively; the sand-LAC compressive strength grew by $45.3 \%$ and $18.1 \%$ for each rate, respectively. It can be seen that as replacement rate increased, the increase of stoneLAC axial compressive strength decreased firstly and then increased, while the increase of sand-LAC axial compressive strength decreased; this behavior is similar to that of the cube compressive strength. The stone-LAC axial compressive strength under each replacement rate increased by $36 \%$, $43.3 \%, 64.8 \%$ and $91.5 \%$, respectively, compared to that of all-lightweight aggregate concrete; sand-LAC axial compressive strength increased by $45.3 \%$ and $71.7 \%$, respectively, compared with all-lightweight aggregate concrete under different replacement rates.

The cube compressive strength of stone-LAC and sand$\mathrm{LAC}$ is linear with the replacement rate. The values of the measured strength were treated with a dimensionless method. The expressions obtained by using the principle of least square method are as follows:

$$
\begin{aligned}
& \text { stone-LAC: } \frac{f_{\mathrm{cu}}}{f_{\mathrm{cu} 0}}=0.52 r+0.96, \quad R^{2}=0.915, \\
& \text { sand-LAC: } \frac{f_{\mathrm{cu}}}{f_{\mathrm{cu} 0}}=0.25 r+1.02, \quad R^{2}=0.879,
\end{aligned}
$$

where $f_{\text {cu0 }}$ represents the cube compressive strength of alllightweight aggregate concrete specimens.

The axial compression strength of stone-LAC and sandLAC is also linear with the replacement rate, and is also treated with a dimensionless method. The expressions 
obtained by using the principle of least square method are as follows:

$$
\begin{aligned}
& \text { stone-LAC: } \frac{f_{\mathrm{c}}}{f_{\mathrm{c} 0}}=0.76 r+1.03, \quad R^{2}=0.963, \\
& \text { sand-LAC: } \frac{f_{\mathrm{c}}}{f_{\mathrm{c} 0}}=0.42 r+1.02, \quad R^{2}=0.958,
\end{aligned}
$$

where $f_{\mathrm{c} 0}$ represents the axial compressive strength of alllightweight aggregate concrete specimens.

According to Technical specification for lightweight aggregate concrete (JGJ 51-2002), the dry apparent densities of stone-LAC and sand-LAC cube specimens in different replacement rates were measured, which were shown in Table 4. It can be seen that the dry apparent densities of stone-LAC and sand-LAC all increase as the increasing of replacement rate. For stone-LAC, the dry apparent density of specified density shale aggregate concrete increased from 1330 to 1940, and the biggest amplitude of variation was $45.9 \%$. For sand-LAC, the dry apparent density of specified density shale aggregate concrete increased from 1330 to 1550 , and the biggest amplitude of variation was $16.5 \%$. The relationship between cube compressive strength and dry apparent density of stone-LAC and sand-LAC are approximately linear, as shown in Figure 7. In other words, the ratio of $f_{\text {cu }}$ and dry apparent density was close to a constant, and based on $f_{\mathrm{cu}}$, the optimum replacement rate was $100 \%$, without the consideration of self-weight.

3.2.2. Splitting Tensile Strength. The splitting tensile strength $\left(f_{\mathrm{ts}}\right)$ of stone-LAC and sand-LAC is shown in Table 5. It can be seen that the splitting tensile strength of specified density shale aggregate concrete increased with the replacement rate in both cases. Natural aggregate has higher strength than that of lightweight aggregate, but the splitting tensile strength of sublightweight concrete still increased as the natural aggregate was replaced by lightweight aggregate. With each increase in replacement rate, the splitting tensile strength growth rate for stone-LAC was 35.1\%, 13\%, 15.3\% and $12.9 \%$, respectively; the splitting tensile strength growth rate for sand-LAC was $20.1 \%$ and $20.2 \%$, respectively. It can be seen that the growth rate of splitting tensile strength for sand-LAC is more stable than that of stone-LAC. The splitting tensile strength of stone-LAC increased by about $35.1 \%, 52.7 \%, 76 \%$ and $98.7 \%$, respectively, more than that of all-lightweight aggregate concrete under different replacement rates; the corresponding increase for sand-LAC was $20.1 \%$ and $44.4 \%$, respectively, when compared with alllightweight aggregate concrete under different replacement rates.

Table 5 shows the splitting tensile strength for stoneLAC to be higher than that of sand-LAC for the same $r$. For $r=50 \%$ and $100 \%$, the splitting tensile strength for stoneLAC was $27.1 \%$ and $37.3 \%$ higher, respectively, than that of sand-LAC. It can be seen that the replacement of ceramsite with crushed stone results in a greater increase of splitting tensile strength than for the replacement of pottery sand with river sand, and the increase became more and more

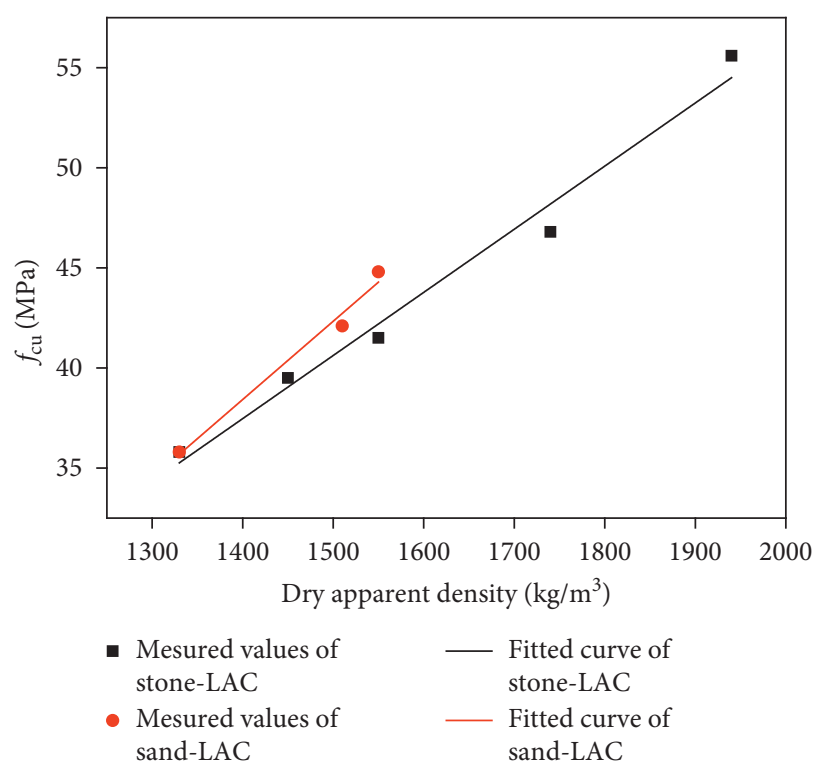

Figure 7: The relationship between cube compressive strength and dry apparent density.

Table 5: Splitting tensile strength of specified density shale aggregate concrete.

\begin{tabular}{lccccc}
\hline$r(\%)$ & 0 & 25 & 50 & 75 & 100 \\
\hline Stone-LAC & 3.13 & 4.23 & 4.78 & 5.51 & 6.22 \\
Sand-LAC & 3.13 & - & 3.76 & - & 4.52 \\
\hline
\end{tabular}

large as replacement rate increases. This is explained by the fact that the coarse aggregate in specified density shale aggregate concrete has a stronger bearing function than that of the fine aggregate from river sand.

The splitting tensile strength of stone-LAC and sandLAC is linear with the replacement rate, and was treated with a dimensionless method. The expressions obtained by the principle of least square method are as follows:

$$
\begin{aligned}
& \text { stone-LAC: } \frac{f_{\mathrm{ts}}}{f_{\mathrm{ts} 0}}=0.90 r+1.06, \quad R^{2}=0.973, \\
& \text { sand-LAC: } \frac{f_{\mathrm{ts}}}{f_{\mathrm{ts} 0}}=0.44 r+0.99, \quad R^{2}=0.995,
\end{aligned}
$$

where $f_{\mathrm{ts} 0}$ indicates the splitting tensile strength of alllightweight aggregate concrete specimens.

3.2.3. Flexural Strength. Measured values for the flexural strength of specified density shale aggregate concrete $\left(f_{\mathrm{f}}\right)$ are shown in Table 6 . It can be seen that the flexural strength of stone-LAC and sand-LAC increased with $r$ for stone and river sand. With each increase in $r$, the stone-LAC flexural strength grew by $10.3 \%, 2.7 \%, 8 \%$, and $9.9 \%$, respectively; the sand-LAC flexural strength grew by $9.8 \%$ and $14.9 \%$, respectively. In comparison to all-lightweight aggregate concrete, the flexural strength of stone-LAC increased by $19.7 \%$, $23.0 \%, 32.8 \%$, and $45.9 \%$, respectively; for sand-LAC, the 
TABLE 6: Flexural strength of specified density shale aggregate concrete.

\begin{tabular}{lccccc}
\hline$r(\%)$ & 0 & 25 & 50 & 75 & 100 \\
\hline Stone-LAC & 6.1 & 7.3 & 7.5 & 8.1 & 8.9 \\
Sand-LAC & 6.1 & - & 6.7 & - & 7.7 \\
\hline
\end{tabular}

flexural strength increase was $9.8 \%$ and $23.0 \%$, respectively. It can be seen that the flexural strength of specified density shale aggregate concrete saw significant improvement, but not to the same degree as was observed for splitting tensile strength.

According to Table 6, the flexural strength of stone-LAC is higher than that of sand-LAC for the same replacement rate. The flexural strength of stone-LAC at $r=50 \%$ and $100 \%$ is $11.9 \%$ and $15.6 \%$ higher, respectively, than that of sandLAC. This behavior is similar to that observed for splitting tensile strength.

The flexural strength of stone-LAC and sand-LAC is linear with the replacement rate, and has also been treated with a dimensionless method. The expressions obtained by using the principle of the least square method are as follows:

$$
\begin{aligned}
& \text { stone-LAC: } \frac{f_{\mathrm{f}}}{f_{\mathrm{f} 0}}=0.40 r+1.04, \quad R^{2}=0.933 \text {, } \\
& \text { sand-LAC: } \frac{f_{\mathrm{f}}}{f_{\mathrm{f} 0}}=0.26 r+0.99, \quad R^{2}=0.965 \text {, }
\end{aligned}
$$

where $f_{\mathrm{f} 0}$ indicates the flexural strength of all-lightweight aggregate concrete specimens.

\subsection{Influence on Indexes of Deformation Performance}

3.3.1. Elastic Modulus. The secant modulus between $0.5 f_{\mathrm{c}}$ and the origin is taken as the elastic modulus $(E)$ for specified density shale aggregate concrete. Measured values of the elastic modulus of stone-LAC and sand-LAC under different replacement rates are shown in Table 7 . It can be seen that the elastic modulus of stone-LAC and sand-LAC gradually increased with $r$ for stone and river sand. The elastic modulus of stone-LAC under each replacement rate increased by $3.26 \%, 6.48 \%, 9.84 \%$, and $15.50 \%$, respectively, more than occurred in all other lightweight concrete. The elastic modulus of sand-LAC under each replacement rate increased by $20.53 \%$ and $30.10 \%$, respectively, more than that of all-lightweight concrete. It can be seen that the addition of stone and river sand resulted in a specified density shale aggregate concrete better able to resist deformation to varying degrees. Under the same replacement rate, the elastic modulus of sand-LAC was higher than that of stone-LAC. When $r=50 \%$ and $100 \%$, the elastic modulus of sand-LAC is $13.2 \%$ and $12.6 \%$, respectively, higher than that of stone-LAC.

The elastic modulus of specified density shale aggregate concrete has no unified empirical formula at present. However, according to the changing rule of the elastic modulus of sublightweight concrete, new empirical formulas can be derived using the elastic modulus of ordinary
TABle 7: Elastic modulus of specified density shale aggregate concrete.

\begin{tabular}{lccccc}
\hline$r(\%)$ & 0 & 25 & 50 & 75 & 100 \\
\hline Stone-LAC & 22.06 & 23.30 & 23.49 & 24.23 & 25.48 \\
Sand-LAC & 22.06 & - & 26.59 & - & 28.70 \\
\hline
\end{tabular}

concrete, and the influence parameters $\alpha$ and $\beta$. This procedure results in the following equations:

$$
\begin{aligned}
& \text { stone-LAC: } E=\frac{10^{5}}{2.2+34.7 / f_{\mathrm{cu} 0}} \alpha, \\
& \text { sand-LAC: } \quad E=\frac{10^{5}}{2.2+34.7 / f_{\mathrm{cu} 0}} \beta .
\end{aligned}
$$

The measured elastic modulus and cube compressive strength of stone-LAC and sand-LAC are taken into Equation (5) to obtain values for $\alpha$ and $\beta$ at each replacement rate, as shown in Table 8.

The fitting formulas for the relationship between $\alpha, \beta$, and $r$ are shown in Equation (6):

$$
\begin{aligned}
\text { stone-LAC: } & \alpha=0.10 r+0.70, \quad R^{2}=0.914, \\
\text { sand-LAC: } & \beta=-0.20(r-1)^{2}+0.90, \quad R^{2}=0.984 .
\end{aligned}
$$

3.3.2. Poisson's Ratio. The average value of Poisson's ratio at $0.2 f_{c}, 0.4 f_{c}, 0.6 f_{c}$, and $0.8 f_{c}$ are taken as Poisson's ratio of specified density shale aggregate concrete $(\gamma)$. Poisson's ratio of stone-LAC and sand-LAC under each replacement rate is shown in Table 9. For stone-LAC, Poisson's ratio decreased and then increased with the rising replacement rate; when $r=25 \%$, Poisson's ratio was the smallest; when $r=100 \%$, Poisson's ratio was the largest. As for sand-LAC, Poisson's ratio decreased as $r$ increased.

\subsection{Conversion Relations of Strength Index}

3.4.1. Compressive Strength Conversion. It can be seen from Table 4 that the values of stone-LAC and sand-LAC are closely related to the replacement rate $r$. Overall, as $r$ increased, $f_{c} / f_{c u}$ for stone-LAC and sand-LAC gradually increased. This relationship is illustrated in Figure 8. It can be seen that when $r<25 \%, f_{\mathrm{c}} / f_{\mathrm{cu}}$ for stone-LAC increases linearly with $r$; when $r>25 \%, f_{c} / f_{\text {cu }}$ remained essentially constant at 0.85 . For sand-LAC, $f_{\mathrm{c}} / f_{\mathrm{cu}}$ increases linearly with $r$. The above behaviors are presented in the following mathematical formula:

$$
\begin{aligned}
& \frac{f_{\mathrm{c}}}{f_{\mathrm{cu}}}=\left\{\begin{array}{ll}
0.64 r+0.69, & r \leq 0.25, \\
0.85, & 0.25<r \leq 1,
\end{array} \quad R^{2}=1.000,\right. \\
& \frac{f_{\mathrm{c}}}{f_{\mathrm{cu}}}=0.28 r+0.70 \quad 0 \leq r \leq 1 \quad R^{2}=0.965 .
\end{aligned}
$$

3.4.2. Tensile and Compressive Ratios. The ratio between the splitting tensile strength and the cube compressive strength 
TABLE 8: Measured values of coefficients $\alpha$ and $\beta$.

\begin{tabular}{lcccrr}
\hline$r(\%)$ & 0 & 25 & 50 & 75 & 100 \\
\hline$\alpha$ & 0.70 & 0.74 & - & 0.74 & 0.77 \\
$\beta$ & 0.70 & 0.84 & - & 0.81 \\
\hline
\end{tabular}

TABle 9: Poisson's ratio of specified density shale aggregate concrete.

\begin{tabular}{lcccrr}
\hline$r(\%)$ & 0 & 25 & 50 & 75 & 100 \\
\hline Stone-LAC & 0.28 & 0.18 & - & 0.24 & 0.28 \\
Sand-LAC & 0.28 & 0.13 & - & 0.31 \\
\hline
\end{tabular}

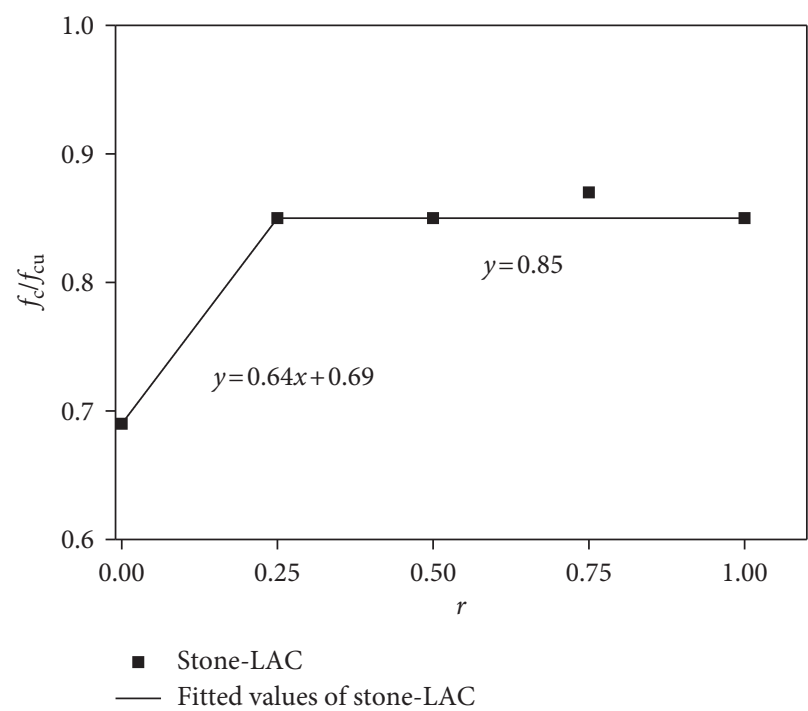

(a)

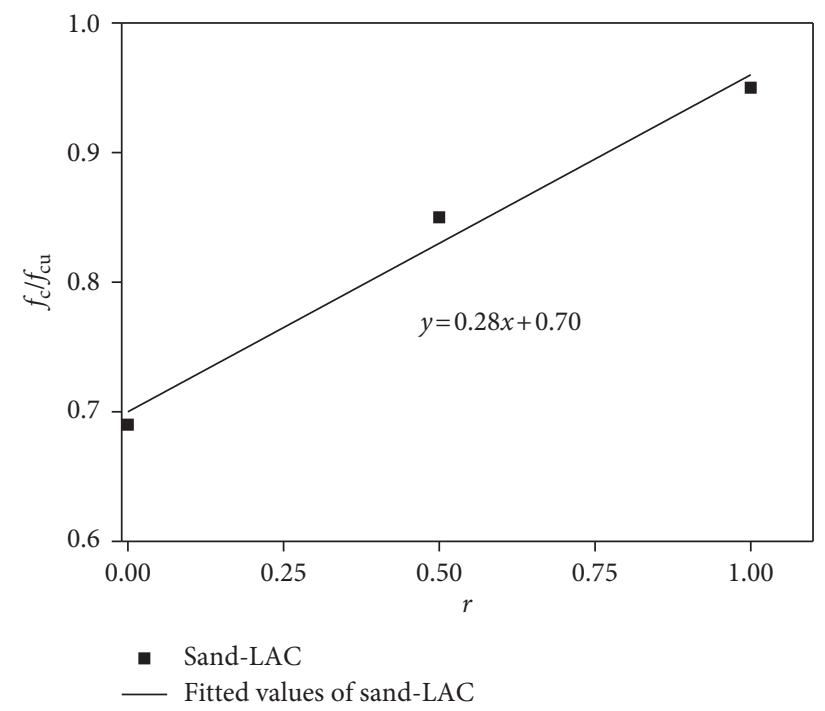

(b)

Figure 8: The relation curves between $f_{\mathrm{c}} / f_{\mathrm{cu}}$ and replacement rate for specified density shale aggregate concrete: (a) stone-LAC; (b) sand-LAC.

$\left(f_{\mathrm{ts}} / f_{\mathrm{cu}}\right)$ of concrete can objectively reflect the relationship between strength and brittleness of concrete. Sun [34] proposed that the tensile ratio of ordinary concrete is only related to Poisson's ratio, and established the relationship between the tensile, compressive, and Poisson's ratios, as shown in Equation (8). However, (8) does not fully apply to the specified density shale aggregate concrete. Equation (9) was derived to account for the specific changes to the tensile and compressive ratios in specified density shale aggregate concrete. Coefficients $A$ and $B$ indicate the impact parameters of stone-LAC and sand-LAC, respectively, and thereby link the tensile and compressive ratios with Poisson's ratio.

$$
\begin{aligned}
\frac{f_{\mathrm{ts}}}{f_{\mathrm{cu}}} & =\frac{2 \gamma^{2}}{1+2 \gamma^{2}}, \\
\frac{f_{\mathrm{ts}}}{f_{\mathrm{cu}}} & = \begin{cases}\frac{2 \gamma^{2}}{1+2 \gamma^{2}} A, & \text { stone-LAC, } \\
\frac{2 \gamma^{2}}{1+2 \gamma^{2}} B, & \text { sand-LAC. }\end{cases}
\end{aligned}
$$

The measured values of the tension and compression's ratio of specified density shale aggregate concrete are shown in Table 10. The undetermined coefficients $A$ and $B$ for stone-LAC and sand-LAC under different replacement rates were calculated from the measured values of tensile, compressive, and Poisson's ratios and are shown in Table 11. A and $B$ can now be related only to $r$ for simplification and are correspondingly plotted in Figure 9. Fitting Equation (10) show that the fitting accuracies are all above 0.9 :

stone-LAC: $A= \begin{cases}0.64+4.48 r, & 0 \leq r \leq 0.25, \\ 0.50+\frac{1}{3.3 r}, & 0.25<r \leq 1,\end{cases}$

sand-LAC: $B=3.96(r+0.2)^{2}+0.60 \quad 0 \leq r \leq 1$.

The replacement rate for stone-LAC and sand-LAC is replaced by Equation (10), respectively. The $A$ and $B$ values are calculated, then inserted into Equation (9) to obtain the calculated values of $f_{\mathrm{ts}} / f_{\mathrm{cu}}$, as shown in Table 12 . 
TABLE 10: Measured tensile and compressive ratios of specified density shale aggregate concrete.

\begin{tabular}{lccccc}
\hline$r(\%)$ & 0 & 25 & 50 & 75 & 100 \\
\hline Stone-LAC & 0.087 & 0.107 & 0.115 & 0.118 & 0.120 \\
Sand-LAC & 0.087 & - & 0.089 & - & 0.100 \\
\hline
\end{tabular}

TABLE 11: Measured values of coefficients $A$ and $B$.

\begin{tabular}{lcccrr}
\hline$r(\%)$ & 0 & 25 & 50 & 75 & \\
\hline$A$ & 0.64 & 1.76 & - & 1.11 & 0.87 \\
$B$ & 0.64 & 2.72 & - & 0.75 \\
\hline
\end{tabular}

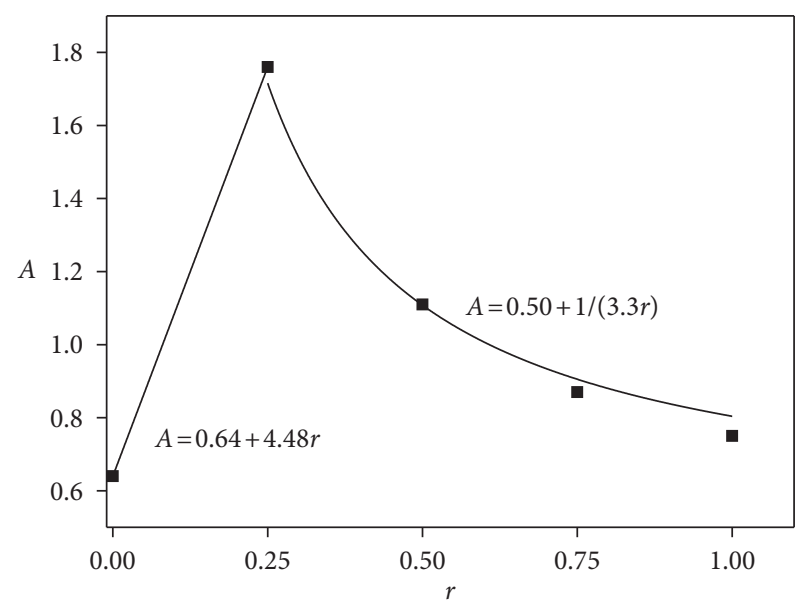

- Measured values

— Fitting curve

(a)

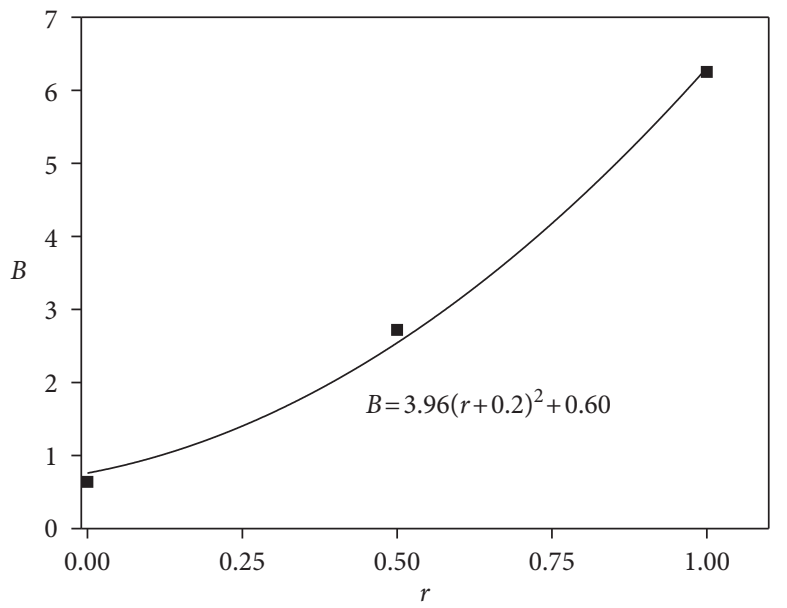

- Measured values Fitting curve

(b)

Figure 9: Relationship curves between $A, B$, and $r$. (a) Relationship between $A$ and r. (b) Relationship between $B$ and $r$ ( $r$ represents the replacement rate of natural stone or sand; $A$ and $B$ are defined as influenced coefficients of $f_{\mathrm{ts}} / f_{\mathrm{cu}}$ for stone-LAC, sand-LAC under different replacement rates, respectively).

TABle 12: Comparison between calculated values and fitted values for $f_{\mathrm{ts}} / f_{\mathrm{cu}}$.

\begin{tabular}{lcccc}
\hline Type & $r(\%)$ & Measured value of $f_{\mathrm{ts}} / f_{\mathrm{cu}}$ & Calculated value of $f_{\mathrm{ts}} / f_{\mathrm{cu}}$ & Calculated value/measured value \\
\hline \multirow{4}{*}{ Stone-LAC } & 0 & 0.087 & 0.088 & 1.01 \\
& 25 & 0.107 & 0.107 & 1.00 \\
& 50 & 0.115 & 0.114 & 0.99 \\
& 75 & 0.118 & 0.123 & 1.04 \\
Sand-LAC & 100 & 0.120 & 0.129 & 1.07 \\
& 50 & 0.087 & 0.816 & 0.94 \\
& 100 & 0.089 & 0.084 & 0.94 \\
\end{tabular}

The average calculated value/measured value ratios for stone-LAC and sand-LAC are 1.02 and 0.96, respectively; the variance are 0.001 and 0.002 , and the coefficient of variation are 0.032 and 0.042 . This statistical analysis indicates that the calculated values of specified density shale aggregate concrete are in good agreement with the measured values.

\section{Conclusions}

Through testing of basic mechanical properties and analysis of specified density shale aggregate concretes, the following conclusions are obtained:

(1) The compressive failure of specified density shale aggregate concrete was caused by ceramsite and 
cement mortar. For flexural failure and splitting tensile failure, the lightweight aggregate was fractured at the failure interface.

(2) When the replacement rate of stone and river sand increased from $0 \%$ to $100 \%$, the cube compressive strength of stone-LAC and sand-LAC linearly increased by $55 \%$ and by $25 \%$, respectively, the axial compressive strength linearly increased by $91 \%$ and by $72 \%$, respectively, splitting tensile strength increased by $99 \%$ and by $44 \%$, respectively, and the flexural strength increased by $46 \%$ and by $26 \%$, respectively.

(3) Increasing the replacement rate for stone-LAC and sand-LAC resulted in $16 \%$ and $30 \%$ increasing, respectively, in their elastic modulus eventually, while Poisson's ratios of sand-LAC decreased by $67 \%$.

(4) Various parameters have been correlated with the replacement rate in this study. These parameters include elastic modulus; the relation between axial compressive strength and cube compressive strength; the relation between compression, tension, and Poisson's ratios. A series of simple calculation models were created from these correlations, and have been shown to be accurate and practical.

In this study, the mechanical failure process and fracture surfaces were analyzed on a macroscopic level. In addition, the control mix proportions for LC35 as related to conversion relations of strength indexes have been determined. However, these relations need to be verified for specified density shale aggregate concrete of other strength grades by additional tests and theoretical analysis. Future work may include techniques such as scanning electron microscopy (SEM), X-ray computed tomography (XCT), etc. to monitor and analyze the mechanical failure of specified density shale aggregate concrete on a microscopic level.

\section{Data Availability}

The data used to support the findings of this study are available from the corresponding author upon request.

\section{Conflicts of Interest}

The authors declare that there are no conflicts of interest regarding the publication of this paper.

\section{Acknowledgments}

This work was financially supported by the Science and Technology Break-through Project of Henan Province (172102210285), the Fundamental Research Funds for the Universities of Henan Province (NSFRF170921), and the Safe Production Project of Key Technology for Major Accident Prevention and Control (Henan-0006-2016AQ). All these are gratefully appreciated.

\section{References}

[1] J. J. Li, J. G. Niu, C. J. Wan, X. Q. Liu, and Z. Y. Jin, "Comparison of flexural property between high performance polypropylene fiber reinforced lightweight aggregate concrete and steel fiber reinforced lightweight aggregate concrete," Construction and Building Materials, vol. 157, pp. 729-736, 2017.

[2] M. C. S. Nepomuceno, L. A. Pereira-De-Oliveira, and S. F. Pereira, "Mix design of structural lightweight selfcompacting concrete incorporating coarse lightweight expanded clay aggregates," Construction and Building Materials, vol. 166, pp. 373-385, 2018.

[3] P. Shafigh, L. J. Chai, H. B. Mahmud, and M. A. Nomeli, "A comparison study of the fresh and hardened properties of normal weight and lightweight aggregate concretes," Journal of Building Engineering, vol. 15, pp. 252-260, 2018.

[4] Y. W. Zhou, X. M. Liu, F. Xing, D. W. Li, Y. C. Wang, and L. L. Sui, "Behavior and modeling of FRP-concrete-steel double-skin tubular columns made of full lightweight aggregate concrete," Construction and Building Materials, vol. 139, pp. 52-63, 2017.

[5] J. A. Bogas and R. Nogueira, "Tensile strength of structural expanded clay lightweight concrete subjected to different curing conditions," KSCE Journal of Civil Engineering, vol. 18, no. 6, pp. 1780-1791, 2014.

[6] H. Z. Cui, T. Y. Lo, S. A. Memon, and W. Xu, "Effect of lightweight aggregates on the mechanical properties and brittleness of lightweight aggregate concrete," Construction and Building Materials, vol. 35, pp. 149-158, 2012.

[7] A. G. Khoshkenari, P. Shafigh, M. Moghimi, and H. B. Mahmud, "The role of $0-2 \mathrm{~mm}$ fine recycled concrete aggregate on the compressive and splitting tensile strengths of recycled concrete aggregate concrete," Materials and Design, vol. 64 , pp. 345-354, 2014.

[8] W. Dong, X. D. Shen, H. J. Xue, J. He, and Y. Liu, "Research on the freeze-thaw cyclic test and damage model of Aeolian sand lightweight aggregate concrete," Construction and Building Materials, vol. 123, pp. 792-799, 2016.

[9] X. F. Wang, C. Fang, W. Q. Kuang, D. W. Li, N. X. Han, and F. Xing, "Experimental investigation on the compressive strength and shrinkage of concrete with pre-wetted lightweight aggregates," Construction and Building Materials, vol. 155, pp. 867-879, 2017.

[10] M. Davraz, M. Koru, and A. E. Akdağ, "The effect of physical properties on thermal conductivity of lightweight aggregate," Procedia Earth and Planetary Science, vol. 15, pp. 85-92, 2015.

[11] K. Onoue, H. Tamai, and H. Suseno, "Shock-absorbing capability of lightweight concrete utilizing volcanic pumice aggregate," Construction and Building Materials, vol. 83, pp. 261-274, 2015.

[12] İ. B. Topçu and B. Işıkdağ, "Effect of expanded perlite aggregate on the properties of lightweight concrete," Journal of Materials Processing Technology, vol. 204, no. 1-3, pp. 34-38, 2008.

[13] O. Sengul, S. Azizi, F. Karaosmanoglu, and M. A. Tasdemir, "Effect of expanded perlite on the mechanical properties and thermal conductivity of lightweight concrete," Energy and Buildings, vol. 43, no. 2-3, pp. 671-676, 2011.

[14] Y. Z. Zhuang, C. Y. Chen, and T. Ji, "Effect of shale ceramsite type on the tensile creep of lightweight aggregate concrete," Construction and Building Materials, vol. 46, no. 8, pp. 13-18, 2013. 
[15] Z. M. Cao, Z. G. He, and Y. Yang, "Experimental study on the influence of water cement ratio on the compressive strength of shale ceramsite concrete," Applied Mechanics and Materials, vol. 204-208, pp. 3895-3898, 2012.

[16] W. J. Yang, Y. D. Yang, and Y. Yang, "Study on water permeability and chloride penetrability of the shale Ceramsite Concrete," Advanced Materials Research, vol. 403-408, pp. 439-443, 2011.

[17] T. F. Deng and J. F. Li, "Study on preparation of thermal storage ceramic by using clay shale," Ceramics International, vol. 42, no. 16, pp. 18128-18135, 2016.

[18] Z. B. Bundur, M. J. Kirisits, and R. D. Ferron, "Use of prewetted lightweight fine expanded shale aggregates as internal nutrient reservoirs for microorganisms in bio-mineralized mortar," Cement and Concrete Composites, vol. 84, pp. 167174, 2017.

[19] C. Q. Wang, X. Y. Lin, D. Wang, M. He, and S. L. Zhang, "Utilization of oil-based drilling cuttings pyrolysis residues of shale gas for the preparation of non-autoclaved aerated concrete," Construction and Building Materials, vol. 162, pp. 359-368, 2018.

[20] M. Rodgers, G. Hayes, and M. G. Healy, "Cyclic loading tests on sandstone and limestone shale aggregates used in unbound forest roads," Construction and Building Materials, vol. 23, no. 6, pp. 2421-2427, 2009.

[21] M. R. Demerchant, A. J. Valsangkar, and A. B. Schriver, "Plate load tests on geogrid-reinforced expanded shale lightweight aggregate," Geotextiles and Geomembranes, vol. 20, no. 3, pp. 173-190, 2002.

[22] A. Lotfy, K. M. A. Hossain, and M. Lachemi, "Lightweight self-consolidating concrete with expanded shale aggregates: modelling and optimization," International Journal of Concrete Structures and Materials, vol. 9, no. 2, pp. 185-206, 2015.

[23] Y. C. Gokhale, R. S. Shukla, and P. K. Jain, "Benefication of shale aggregate and production of artificial aggregate," Bulletin of the International Association of Engineering GeologyBulletin de l'Association Internationale de Géologie de l'Ingénieur, vol. 30, no. 1, pp. 391-393, 1984.

[24] C. Tasdemir, O. Sengul, and M. A. Tasdemir, "A comparative study on the thermal conductivities and mechanical properties of lightweight concretes," Energy and Buildings, vol. 151, pp. 469-475, 2017.

[25] Y. Zaetang, A. Wongsa, V. Sata, and P. Chindaprasirt, "Use of lightweight aggregates in pervious concrete," Construction and Building Materials, vol. 48, no. 11, pp. 585-591, 2013.

[26] M. I. Kaffetzakis and C. G. Papanicolaou, "Bond behavior of reinforcement in lightweight aggregate self-compacting concrete," Construction and Building Materials, vol. 113, pp. 641-652, 2016.

[27] N. M. Miller and F. M. Tehrani, "Mechanical properties of rubberized lightweight aggregate concrete," Construction and Building Materials, vol. 147, pp. 264-271, 2017.

[28] M. Aslam, P. Shafigh, M. A. Nomeli, and M. Z. Jumaat, "Manufacturing of high-strength lightweight aggregate concrete using blended coarse lightweight aggregates," Journal of Building Engineering, vol. 13, pp. 53-62, 2017.

[29] Q. M. Ma, R. X. Guo, Y. L. Sun et al., "Behaviour of modified lightweight aggregate concrete after exposure to elevated temperatures," Magazine of Concrete Research, vol. 70, no. 5, pp. 217-230, 2018.

[30] S. Y. Chung, M. A. Elrahman, P. Sikora, T. Rucinska, E. Horszczaruk, and D. Stephan, "Evaluation of the effects of crushed and expanded waste glass aggregates on the material properties of lightweight concrete using image-based approaches," Materials, vol. 10, no. 12, 1354 pages, 2017.

[31] Y. Xu, L. H. Jiang, J. X. Xu, and Y. Li, "Mechanical properties of expanded polystyrene lightweight aggregate concrete and brick," Construction and Building Materials, vol. 27, no. 1, pp. 32-38, 2012.

[32] J. J. Li, Y. H. Chen, and C. J. Wan, “A mix-design method for lightweight aggregate self-compacting concrete based on packing and mortar film thickness theories," Construction and Building Materials, vol. 157, pp. 621-634, 2017.

[33] P. Suttaphakdee, N. Dulsang, N. Lorwanishpaisarn, P. Kasemsiri, P. Posi, and P. Chindaprasirt, "Optimizing mix proportion and properties of lightweight concrete incorporated phase change material paraffin/recycled concrete block composite," Construction and Building Materials, vol. 127, pp. 475-483, 2016.

[34] N. P. Sun, "Research on tension and compression's ratio of concrete," Building Science, vol. 30, no. 7, pp. 19-22, 2014, in Chinese. 


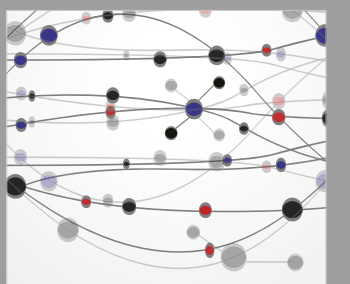

The Scientific World Journal
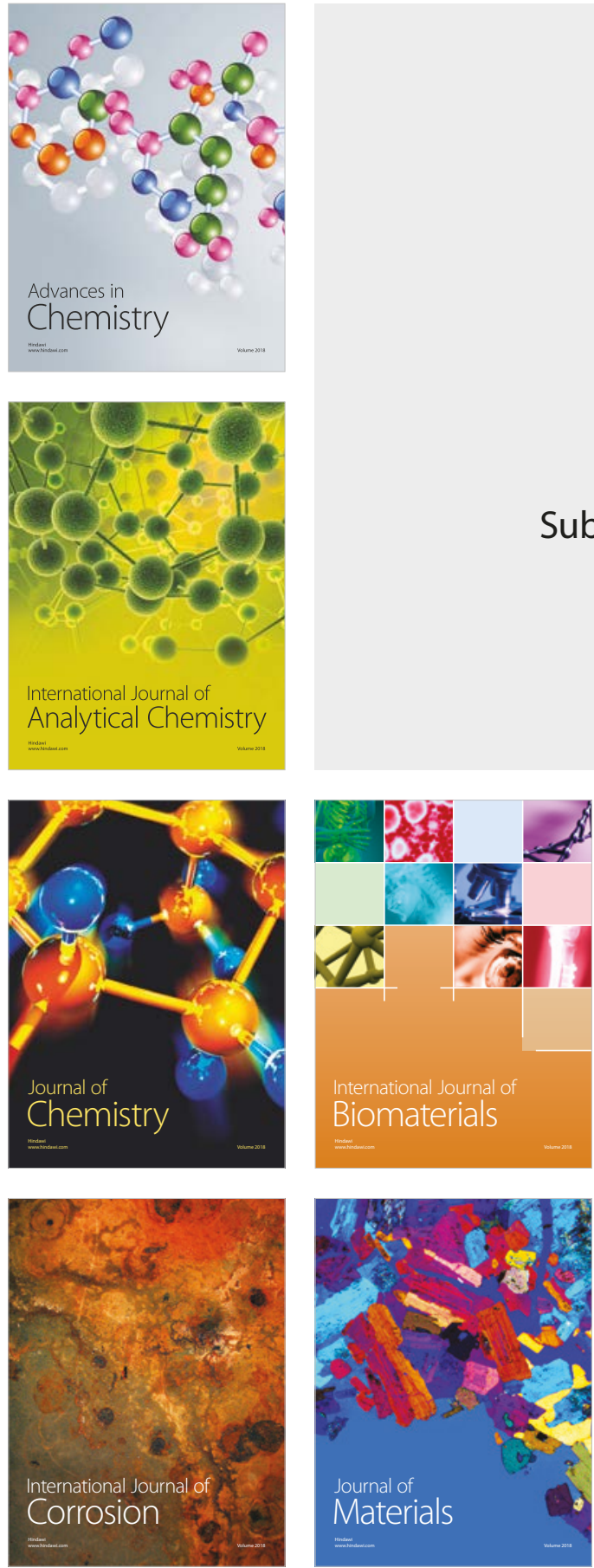

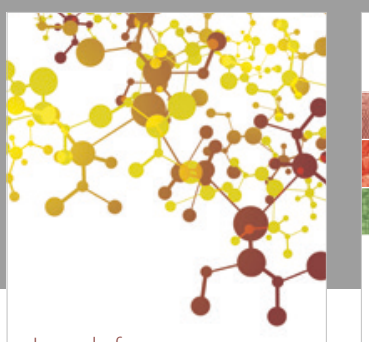

Journal of

Applied Chemistry
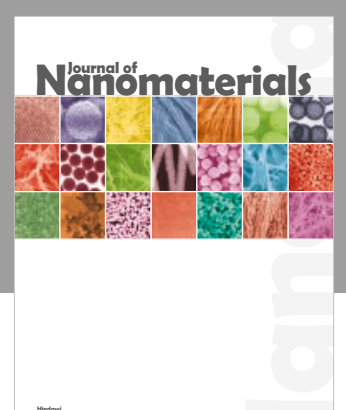

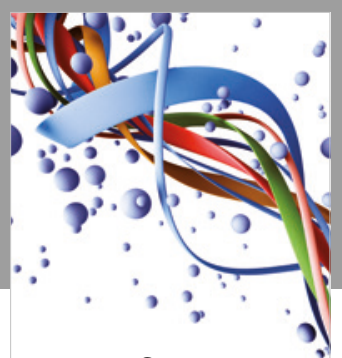

Scientifica

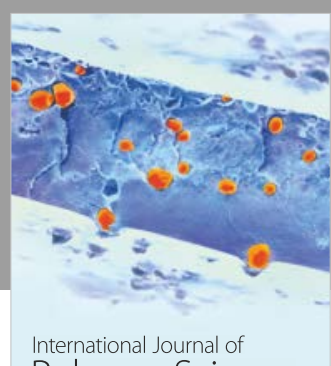

Polymer Science

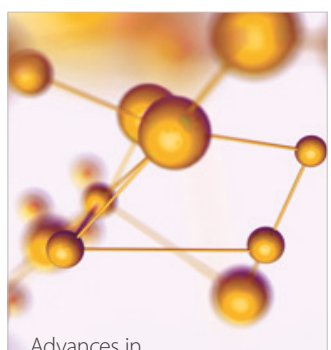

Physical Chemistry
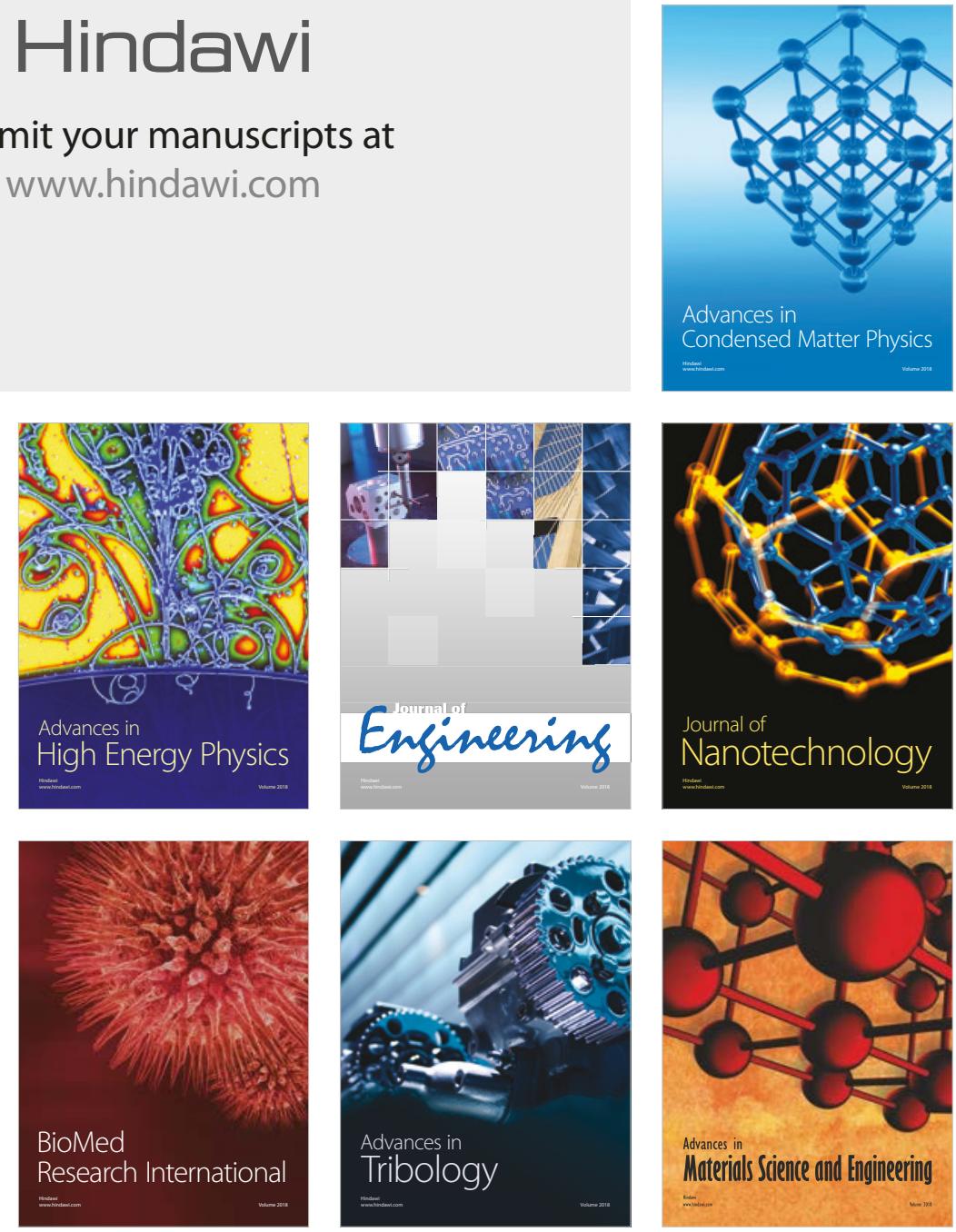